Family Medicine and Community Health

\title{
Non-communicable disease care and physical activity promotion in India: analysis of recent policies, guidelines and workplans
}

\author{
Satyajit Mohanty (D) , ${ }^{1}$ Epari Venkatarao, ${ }^{1}$ Sandul Yasobant ${ }^{2}$
}

To cite: Mohanty S,

Venkatarao E, Yasobant S. Noncommunicable disease care and physical activity promotion in India: analysis of recent policies, guidelines and workplans.

Fam Med Com Health 2020;8:e000206. doi:10.1136/ fmch-2019-000206

- Additional material is published online only. To view please visit the journal online (http://dx.doi.org/10.1136/fmch2019-000206).
Check for updates

(C) Author(s) (or their employer(s)) 2020. Re-use permitted under CC BY-NC. No commercial re-use. See rights and permissions. Published by BMJ.

${ }^{1}$ Community Medicine, Siksha 0 Anusandhan University, Bhubaneswar, Orissa, India

${ }^{2}$ Center for Development Research, University of Bonn, Bonn, Nordrhein-Westfalen, Germany

Correspondence to Dr Satyajit Mohanty; satyajit.mohanty74@gmail.com

\section{ABSTRACT}

Burden statements on non-communicable diseases (NCDs) across the globe suggest that they pose a constant threat to human development. There are two different types of NCD interventions: population-based interventions addressing NCD risk factors and individual-based interventions addressing NCDs in the primary care setting. Most of the individual-based interventions are based on NCD-care models, as opposed to population-based interventions targeting risk factors through independent vertical programmes. We explored the relevant Indian policy documents including the recent National Health Policy 2017, to get an overview of the Indian NCD-care model and to find out how physical activity $(\mathrm{PA})$ promotion stands in the year 2019 in the current policy documents on NCDs. We conducted a review with two perspectives; first to capture the NCD-care models and second to document the PA promotion and its integration in the current NCDcare model specific to the Indian context. Indian NCD programme is an evolving healthcare programme with a definite NCD-care model, where the individual-based and population-based care are thoroughly linked. Despite having good NCD-care policy and methodical planning, PA promotion seems to be lacking in the policy perspective and currently physical inactivity as a risk factor is not considered seriously. The structure of the NCD-care model should be detailed and strengthened by incorporating lessons from other successful NCD models from across the globe. Indian NCD model must provide sufficient scope of interfacing individual care to that of population-based risk factor strategies like physical activity promotion.

\section{INTRODUCTION}

Burden statements on non-communicable diseases (NCDs) across the globe suggest that they pose a constant threat to human development. ${ }^{1}$ Management of NCDs requires a different approach and also it requires strategic changes leading to optimum transformation in all facets of healthcare. There are two different types of NCD interventions, that is, population-based interventions addressing NCD risk factors and individual-based interventions addressing NCDs in the primary care setting. ${ }^{2}$ Most of the individual-based

\section{Key points}

What is this research focused on exploring, validating or solving?

- This piece of research is aimed at exploring the Indian policies on non-communicable diseases (NCDs) focusing on NCD-care model and physical activity promotion therein.

What conclusions did this research draw through design, method and analysis?

- The study concluded that there is an appropriate NCD-care model but there is absence of an appropriate physical activity promotion strategy.

What is the value, meaning and impact of this research? Is there any follow-up study based on this research?

- The study suggests formulation of a national physical activity programme to appropriately promote physical activity at the population level so that lacunae in the policy level could be bridged. This would help to take care of the NCD threat posed over the Indian subcontinent.

interventions are based on NCD-care models, as opposed to population-based interventions targeting risk factors through independent vertical programmes. Both interventions must be appropriately interfaced to achieve a population-level change. ${ }^{34}$

The chronic care model (CCM) is regarded as one of the prominent models for NCDcare among various NCD-care models operationalised globally. CCM emphasises linking informed and activated patients to a prepared healthcare team. The CCM suggests six areas to improve NCD care or chronic illness care. They are health systems organisation of care, community resources and policies, self-management support, decision support, delivery system design and clinical information system. ${ }^{5}$

Population-based risk factor control is one of the major strategies for primary prevention 
and control of NCDs. 'Physical activity' (PA) is one of the 'best buys' for NCDs that an individual and a country as a whole can adopt. ${ }^{6}$ To scale up PA at the population level, several countries around the world have designed their National Physical Activity Policies (NPAPs), which aim to achieve the level set by the physical activity guidelines (PAGs) of that country. NPAPs of many countries are exclusive plans to promote PA. ${ }^{6-9}$ India too has a PAG, but it lacks a National physical activity policy. PA promotion is covered under integrated NCD policy. ${ }^{10} 11$

According to the ICMR-INDIAB study, ${ }^{12}$ in India of the three domains of PA viz. work, transport and recreation, most time spent in a moderate to vigorous PA was at workplace which averaged $46 \mathrm{~min}$ per day, whereas an average of 14 and $20 \mathrm{~min}$ per day is being spent on transport and recreational PA, respectively. The same study reported that males spend more in moderate to vigorous PA than females, suggesting gender as one of the important factors of the 11 different factors (social norms, religious values, security situations, availability of safe public places for PA, geographical settings, season/climate and gender) suggested by WHO to look into before adopting global recommendations of PA into any national policy. According to $\mathrm{WHO}$, in southeast Asia, the higher prevalence of physical inactivity among females is more likely due to social and cultural factors rather than biological. ${ }^{13}$

Introducing PA for public health in high-income countries like the USA is relatively different owing to the lower population density, pollution-free environment, safe PA spaces and above all costs for providing all avenues for PA. Thus, WHO has recommended a different model for lowincome to middle-income countries. PA models adopted by Brazil or from high-income countries like Singapore are more replicable in the Indian context. ${ }^{14} 15$ In Singapore, the operationalised model is based on four main components viz. a month-long national healthy lifestyle campaign, workplace-based programmes, communitybased programmes and healthy lifestyle ambassador awards.

In India, a new National Health Policy (NHP) was pronounced, 15 years after the last one in 2002, looking at the rapid health transition it is going through. ${ }^{16}{ }^{17}$ Extending the work of the last health policy in 2002, an elaborate focus is laid on the NCDs in this new policy document because of the pandemic of NCDs in the Indian subcontinent inhabiting approximately one-seventh of the global population with close to $60 \%$ of the population estimated to be below 30 years.

However, much before the recent NHP, in the year 2010, Ministry of Health and Family Welfare, Government of India, launched the National Programme for Prevention and Control of Cancer, Diabetes, Cardiovascular Diseases and Stroke (NPCDCS) with the objectives to prevent and control common NCDs through behaviour and lifestyle changes, and to provide early diagnosis and management of common NCDs. ${ }^{18}$ In the year 2015, India became the first country to adopt the global monitoring framework suggested by WHO. ${ }^{19}$ This implies by now India should be ready to check the progress in terms of both preventive and therapeutic measures taken to curb and fight NCDs.

On the contrary, WHO apprehend that the laid down sustainable development goals for the year 2030 concerning NCDs may not be achieved because of weak current policy commitments and their respective responses from many countries. ${ }^{1}$ Looking at the progress of NCD care in the Indian subcontinent, the same concerns have been echoed by Indian think tanks and news agencies. ${ }^{20}$

With this backdrop, we explored the relevant Indian policy documents including the recent NHP 2017, to get an overview of the Indian NCD-care model and to find out how PA promotion stands in the year 2019 in the current policy documents on NCDs with the following two pre-set questions:

1. Do the policies reveal any definitive model of NCD care independent of the prevailing acute care model? If there is a definitive model for NCD care, whether it is expansive enough to capture both interventions (population and individual level)?

2. Whether the PA promotion as primary prevention is appropriately strategised in those policies for NCD control? Whether it is adequately interfaced with the current NCD-care model (if found any)?

\section{METHODS}

We conducted a review with two perspectives; first to capture the NCD care models and second to document the PA promotion and its integration in the current NCDcare model specific to the Indian context.

Both the published and grey literature (materials and research produced by organisations outside of the traditional commercial or academic publishing and distribution channels) were targeted for the screening. All the policies, guidelines and work plan documents related to NCD care including PA model were reviewed from the databases like web pages of Government of India, National/International organisations and major online libraries as shown (see online supplementary table 1).

In addition, relevant literature was searched in PubMed, Cochrane database and Google Scholar that discussed the same issue, which was applicable in the Indian context. In PubMed, we used the following search strategy: ("India" OR "Indian") AND ("Non-communicable disease*" OR "NCD" OR "NCD burden" OR "NCD morbidity" OR "Physical Activity" OR "Physical Exercise" OR "Physical inactiv*" OR "Physical function" OR "Physical performance" OR "Physical activity promotion") AND ("policy" OR "guideline*" OR "action" OR "plan" OR "Strategy" OR "approach" OR "protocol" OR "scheme" OR "program"). Prior to the development of search terms, we looked for appropriate MeSH terms and applied with maximal truncations. A total of 29 documents were identified through webpage searching and in addition, 10 documents were identified through other sources (grey). After removing duplicates, 31 records were available for 


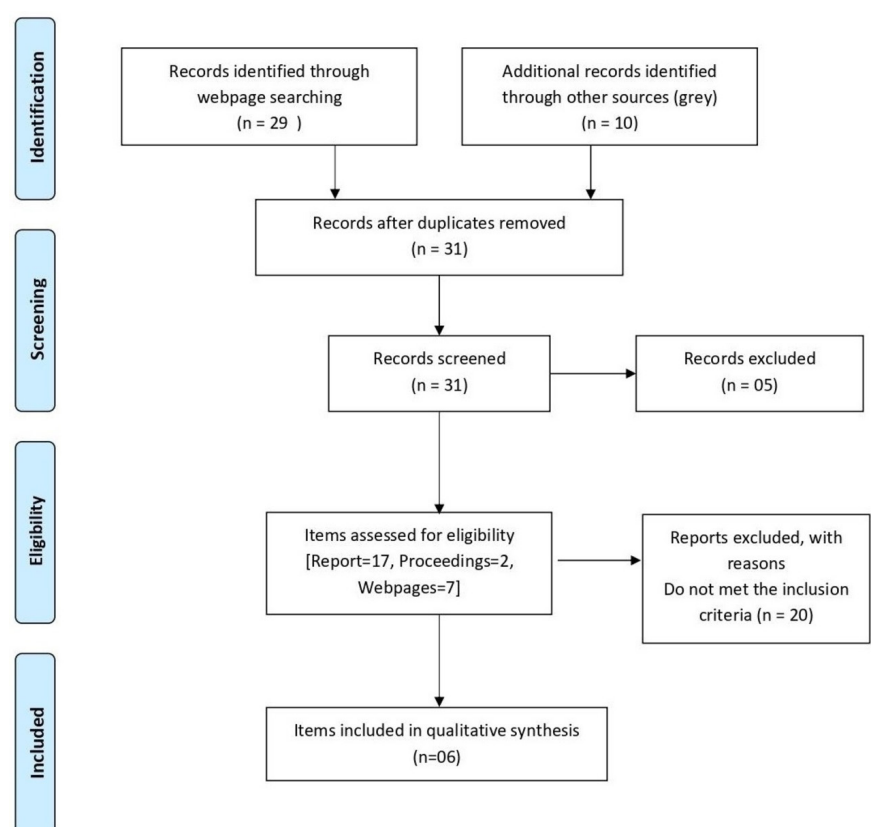

Figure 1 PRISMA chart indicating the systematic search.

scrutiny. Documents which did not discuss PA exclusively (5) and those that did not match the inclusion criteria (17 reports, 2 proceedings, 7 webpages) were left out of the final analysis. Figure 1 describes the final list of the documents reviewed.

In the search, the duration of publication of articles was limited to a period from the year 2000 to 2019. Only English-language documents were included for the review. Two independent researchers reviewed the available literature and the third author resolved final conflicts if any.

\section{RESULTS}

The following documents related to NCD care and PA promotion for prevention of NCDs were extracted and included for the review:

a. Report of the Working Group on Disease Burden for the 12th Five Year Plan. Vol. 3. ${ }^{21}$

b. National Action Plan 2012 for Non-Communicable Diseases $^{22}$

c. National Health Policy (2017). ${ }^{17}$

d. The PAG in India. ${ }^{11}$

e. Key guidelines for prevention and control of noncommunicable diseases (National health mission, Himachal Pradesh). ${ }^{23}$

f. Work plan for NCD-related programmes (National health mission, Himachal Pradesh) ${ }^{23}$

These documents presented here can broadly be divided into three. Before the national health policy of 2017, how the disease burden with respect to NCDs looked like and how the action plans, guidelines and state-level work plans are shaping up with respect to PA as a preventive intervention with Indian PAG as a reference.

\section{DISCUSSION}

Population-level PA promotion begins with the induction of an appropriate policy. The starting point for this is to have a vision document based on current and future problems. Further, short-term and long-term goals are to be prepared based on the vision document. Depending on these goals, the work plans are to be formulated. This paper tries to indicates the absence of PA policy which in turn points towards inadequate planning. This paper also emphasises the fact that inadequate PA policy may affect the overall NCD care and the success of NCD policy.

Both acute and chronic care was being provided from a single service delivery platform until the recent health policy. ${ }^{172122}$ Only lately, separate NCD clinics have been set up. However, there is no explicit discussion on the model of NCD care in these policy documents. In the past, since the 1980s new NCD programmes were started on a low scale in a limited number of districts. As per the surveillance data from these districts, there has not been considerable change in the burden of NCDs presumably because of these low-scale interventional programmes. Hence, it was recommended that there is a need to emphasise on health promotion and preventive measures to reduce exposure to risk factors. ${ }^{3}$ Also, it is important to understand that the national policies are important to reduce the exposure to a risk factor (physical inactivity) in the context of NCD prevention. Further, publicising and promoting PA may help the NCD-care scenario in two ways. First, it is expected that increasing awareness regarding PA will lead to increased self-care at the individual level. Second, this will facilitate the provider care and also close the gap between NCD services and demand for NCD services at the population level.

\section{Part 1: Envisaging the NCD-care model of India}

Structural arrangement of Indian healthcare network: Indian healthcare is a three-tier hierarchical arrangement, namely primary, secondary and tertiary healthcare. Primary healthcare infrastructure consists of subcentres, primary health centres (PHCs) and community health centres (CHCs). Secondary healthcare infrastructure consists of subdivisional hospitals, area hospitals, District and Urban hospitals; and Tertiary healthcare infrastructure consists of medical colleges and apex referral centres. ${ }^{24}$ Each of the three levels is entrusted with different responsibilities yet ensuring 'continuity of care' (table 1$).^{17}$

Public health, primary healthcare and social welfare structures are envisaged as the horizontal programmes which are engaged with 'dual burden' of dealing with the individualised interventional care and health promotional activities. Similarly, population-based strategies dealing with risk factor control of NCDs are envisaged as vertical programmes. As both population-based interventions (NCD-related risk factor control) and individualbased interventions are practised at the level of primary healthcare, it is suggested that both the horizontal and vertical programmes must be integrated at this level for optimum impact on NCD scenario. ${ }^{4}$ 
Table 1 Current pattern of healthcare infrastructure in India relevant to NCD care

\begin{tabular}{ll}
\hline Health infrastructure & Key functions for NCDs \\
\hline Primary healthcare & $\begin{array}{l}\text { Primary prevention and basic-level NCD care: Health promotion, screening, follow-up, referral and } \\
\text { basic level NCD management at CHCs and home-based care at CHCs }\end{array}$ \\
Secondary healthcare & $\begin{array}{l}\text { Secondary prevention and advanced care: Early diagnosis and management of all NCDs except } \\
\text { cancers requiring radiotherapy, complicated cases of renal diseases, cardiac cases requiring surgery, } \\
\text { retinal diseases, NCDs requiring laser treatment, organ transplantations }\end{array}$ \\
Tertiary healthcare & $\begin{array}{l}\text { Tertiary prevention and comprehensive care: comprehensive cancer treatment, cardiac care including } \\
\text { cardiac surgery, neurosurgery, organ transplantation, tertiary-level care for ENT, ophthalmology, } \\
\text { geriatrics, etc }\end{array}$
\end{tabular}

Indian health facilities have a pyramidal structure tapering at the top with tertiary health care. ${ }^{24}$

$\mathrm{CHC}$, community health centre; NCD, non-communicable disease.

Key foundations of NCD-care programmes in India ${ }^{17}$ :

1. Sensitisation: ' $4 \times 4$ model' of four diseases and four lifestyle risk factors explain the majority of the world's burden of NCDs across all the economies of the world. ${ }^{25}$ To gain control over them, risk factors are targeted by independent programmes. And there are six major independent vertical NCD programmes underway by the Ministry of Health, Government of India as described in box 1.

At the ground level, the primary healthcare system sensitises and creates an appropriate foothold for these programmes by generating activated and wellinformed patients from the community. They also help bring patients into the healthcare system. However, other health promotion mechanisms, for example, propaganda through TV advertisements on tobacco and cancer, bring patients under the healthcare umbrella. These programmes are policy-backed activities.

2. Community reach: Screening and health promotion are guaranteed by multitasking agents like Community Health Workers (ASHA). Further, these field workers ensure adequate community reach for all governmentrun health programmes. ${ }^{17}$

3. Point of entry: In order to cater to the needs of activated and well-informed patients, a prepared healthcare team is present at every level of healthcare from primary to tertiary. Further, three different service delivery models are currently operating in the Indian healthcare system.

a. Mixed care service delivery where both acute care, chronic care services, that is, communicable disease

\section{Box 1 Independent vertical health programmes relevant to NCD care in India}

1. NPCDCS=National Program for Prevention and Control of Cancer, Diabetes, Cardiovascular Diseases and Stroke

2. NPHCE $=$ National Program for Health Care of Elderly

3. NMHP=National Mental Health Program

4. NTCP $=$ National Tobacco Control Program

5. NAP=National Alcohol Policy

6. Newer components: Injury and COPD prevention
(CD), non-communicable disease (NCD) services run simultaneously.

b. Exclusive service delivery dealing only with NCDs.

c. Comprehensive service delivery facilities are called 'Health and wellness centres'. These centres include both the selective service delivery modes described under $\mathrm{a}$ and $\mathrm{b}$ along with geriatric healthcare, palliative and rehabilitative care services.

4. Referral system: The referral system is well organised within the three-tier hierarchical pyramidal arrangement of Indian health facilities. It ensures adequate care at each level and it also offers flexible multiple points of entry for the patients to any of the care levels mentioned previously.

5. Data linking: There is a future provision for standardised access to health records of the patients. AADHAAR linked registries (ie, patients, providers, services, diseases, documents and events) will ensure successful data sharing making the different levels of care into a system of 'continuum of care'. Simultaneously, it will also augment health research through enhanced public health/big data analytics.

6. Supply chain framework: There are three different supply chains in the current NCD-care model.

a. The supply chain for human resources: To ensure the unceasing supply of medical, paramedical and other support staff for the healthcare industry.

b. The supply chain for knowledge: To upgrade and enhance up-to-date practices, adequate training systems are available across all the levels of the workforce in the healthcare industry to deal with different aspects of NCDs.

c. The supply chain of medicines and equipment.

7. Palliative, rehabilitative and home-based care: The healthcare system has started outreaching to the patients through rehabilitative services, hence more attention is paid to rehabilitative care recently. This arrangement has the potential to elevate the current healthcare system from 'continuum of care' to 'comprehensive continuum of care' that assists people in their home environment to deal with NCDs.

8. Interfacing of the individual-based and populationbased interventions: Programmes for risk factor 
control are the means of primary prevention. These programmes for NCD risk factors like PA promotion, alcohol and tobacco control are conducted from various levels of the public health facility as vertical programmes. ${ }^{26}$ Due to this, there is adequate interfacing of individual-based programmes and population-based interventions. This two-way systemic linkage at various levels of care enforces 'continuum of care'. In addition, the public health system is arranged as a gatekeeping mechanism at the primary level. So, it can safely be assumed that the NCD-care model is thoroughly linked to population services.

In a nutshell, NCD-care model refers to the NCD management framework or its strategic orientation to deal with NCDs accommodating all levels of prevention. ${ }^{5}$ Indian NCD programme is an evolving healthcare programme with a definite NCD-care model, where the individual-based and population-based care are thoroughly linked to each other ensuring the future success of the NCD-care system.

Part 2: PA promotion as reflected in the policy documents and its integration in the current NCD-care model

Before embarking on to the review of the policy documents, a quick review of three important recent initiatives has revealed optimism for promotion of PA with few lacunae.

The 'Smart City initiative': The smart city mission was launched in 2015. The smart city is a habitation, where there is easy access to all amenities and facilities of dayto-day life. This, in turn, reflects easy access to physical activity. Inhabitants are encouraged for PA in the form of walking, tracks for cycling, well-located safe parks and public transport. This is also referred to as 'active mobility. ${ }^{27}$

The 'Fit India movement': Fit India movement was announced on 29 August 2019 on the eve of the National sports day aiming to promote the health and well-being of all Indian nationals. The programme is placed under the ministry of youth affairs and sports. ${ }^{28}$

The 'Khelo India' programme: Similarly, this programme is again sponsored by the ministry of youth affairs and sports. Currently, it is promoting university-level sports activities. Similar to 'Fit India movement', it also seems to target the younger mass only. ${ }^{29}$

Summarising the current scenario, two of the three programmes mentioned are under the sports ministry. As physical inactivity has multiple links to chronic diseases, it is highly suggested that promoting PA should ideally be tackled by 'health promotion' through the department of health and family welfare; not just through the sports ministry. The aforesaid programmes are discrete in nature without having an appropriate policy backbone for promoting PA at the population level. More importantly, emphasis on 'physical activity' seems to be missing and the target audience is a subpopulation, especially the young. There is a need to bring all of the PA promotion programmes under a single umbrella encompassing the depth and breadth of the entire population.

\section{i. Absence of an independent vertical programme on PA}

Policy documents do not reflect the vision for the formulation of a PA plan.

a. The policy document "National Action Plan 2012 for Non-Communicable Diseases" $" 22$ articulates the way to control risk factors and the key actions that are to be taken at various levels of the healthcare system in order to achieve national NCD targets. Targets are set strategically and executed under apex implementing bodies. For example, in order to achieve a $30 \%$ relative reduction in the prevalence of tobacco use, an independent vertical programme like "National Tobacco Control Programme" is responsible for development of strategies and subsequent execution, while in order to achieve a target $10 \%$ relative reduction in the prevalence of insufficient PA, no such strategic body is present as reflected in the document.

b. Further, in the "National Action Plan 2012 for NonCommunicable Diseases", ${ }^{22}$ in order to achieve targets like a $25 \%$ relative reduction in the prevalence of raised blood pressure and halt the rise in obesity and diabetes prevalence, NPCDCS is the overarching strategic body responsible for achieving the targets. NPCDCS is one of the 18 different health programmes that exist in the scheme of things under DGHS. ${ }^{30}$ In order to achieve the targets mentioned previously, the promotion of $\mathrm{PA}$ is a suggested activity, but there is not a single programme among those 18 programmes that address the promotion of PA.

c. Indian national NCD programme started way back in 1975 with the National Cancer Control Program and in 2010-2011, six other programmes including the ongoing NPCDCS were added. The Eleventh FiveYear Plan (FYP) witnessed the evolution of NPCDCS by the merger of two programmes, National Cancer Control Program and National Program for Control of Diabetes, Cardiovascular diseases and Stroke. Building on the lessons learnt at the end of the 11th FYP, 12th FYP was set up with nine important strategies. Looking at the first two strategies, the first one advocates health promotion for healthy lifestyles that prevent NCDs and their risk factors, and the second one addresses specific prevention strategies to be developed, which reduce exposure to risk factors. That means 12th FYP is vocal about addressing risk factors of NCDs and physical inactivity is one of the major risk factors under consideration.

In 12th FYP, the scope of programmes on NCDs is discussed under three broad categories consisting of 25 different subheadings. Three broad categories are (1) programmes for lifestyle chronic diseases and risk factors, (2) programmes for disability prevention and rehabilitation, and (3) health promotion and prevention of NCDs. Programmes under the first two are individual interventions, whereas the last one is a 
population-based intervention. The first two categories are concerned with the delivery of individualised treatment and rehabilitation care, but none of them reflects any link or referral to PA promotion programmes to reduce the exposure to physical inactivity at the individual level. This demonstrates an acute deficiency in risk factor control (exposure to physical inactivity) at the individual level. On the other hand, the strongest advocacy for the promotion of PA comes from the programme on "Prevention and control of nutritional disorders and obesity" which is limited only to school health programmes. Hence, only a portion of the population is covered under such a programme. Further, the "National Institute of Health Promotion and Control of Chronic Diseases (NIHCCD)" was supposed to be the main coordinating and facilitating agency for health promotion for the government of India, which is still in its inception stage. The vision of this institute is "promote health by changing lifestyle for the people in India". This institute is aligned with the idea of WHO, which proclaims the most effective and economically productive intervention for NCDs are health promotion interventions. PA promotion is an important health promotional priority. Among six different divisions of NIHCCD, the first division is "Policies, Planning Strategy Development and Coordination Division". Looking at developments of NPAPs of different countries, ${ }^{89}$ our Indian National physical activity plan should be one of the foremost policy planning awaited from NIHCCD. However, it is not clear from the 12th FYP document that such planning is underway.

d. There are two important thrust areas for NHP 2017, one is ensuring adequate investment and the other is preventive and promotive health. NHP 2017 aims at starting a social movement "Swasth Nagrik Abhiyan" by working in a coordinated manner on seven priority areas. Further, NHP 2017 has expressed the need for the development of strategies and institutional mechanisms to address all of these seven priority areas. The second priority area is on balanced nutrition and regular exercise. The most interesting aspect of NHP 2017 is that it has a vision for strengthening the school health programmes so that the school environment would act as a site for preventive health and primary healthcare. AYUSH and Yoga at the workplace, school and community are to be key aspects for health promotion owing to the acceptability in the Indian population. Nonetheless, it misses the underpinning keyword "physical activity promotion". About NCDs, NHP 2017 is more concerned about the screening of NCDs and secondary prevention as a means of reducing the morbidity and mortality caused by NCDs. However, in NHP 2017, there is no indication of creating a specific strategy or institutional mechanisms on PA promotion as a means of primary prevention.

e. While exploring the state-level guidelines and work plans for implementation of PA for the prevention of
NCDs, the National Health Mission division of the state of Himachal Pradesh ${ }^{31}$ revealed that ASHA workers are responsible for the promotion of PA. Health Worker (HW) was second in the line to shoulder the responsibility. No other professional is designated with this responsibility and how PA is to be promoted is unclear.

\section{ii. Allocation of finances for PA programmes}

Currently, the NCD Flexi-pool finances the ongoing National Program for Prevention and Control of Cancer, Diabetes, Cardiovascular Disease and Stroke (NPCDCS), a programme sponsored by the Government of India. It has a reach of up to district level through the National Health Mission. ${ }^{32}$ There are possibilities of allocation of funds for PA promotion under this initiative, for 'schoolbased obesity prevention' under Prevention and Control of Nutritional Disorders and Obesity Program, but exact figures are unknown. However, in the 12th FYP, there is no separate budget allocation for PA promotion. Similarly, health promotion is under the arena of the National Institute of Health Promotion and Control of Chronic Diseases. There is a possibility of funding PA promotions such as public messaging and research under this. However, as discussed earlier, the institute is still in its inception stage.

iii. Targets and accountability regarding PA promotion programmes Exclusive studies on physical inactivity as a prominent risk factor are sparse. ${ }^{26}{ }^{33}$ However, in the year 2015, India became the first country in adapting WHO's Global Monitoring Framework for NCDs. ${ }^{34}$ On the other hand, a target was set in the National Monitoring Framework to reduce the prevalence of physical inactivity by $5 \%$ by the year 2020 and $10 \%$ by the year $2025 .{ }^{35}$ Further, a recognisable action plan to achieve said targets and accountable organisation(s) for the monitoring and execution of the same have not yet been identified in any policy document including the 12th FYP.

Despite having good NCD-care policy and methodical planning, PA promotion seems to be lacking and currently physical inactivity as a risk factor is not considered seriously. Because of the absence of an independent programme on the promotion of PA, it can safely be presumed that PA promotion is not integrated into the current NCD-care model.

\section{Cautionary remarks}

A weak PA policy can be an obstacle for meeting NCD targets: Insufficient PA is linked to the predisposition of many NCDs and on the contrary adequate daily PA affords protection against those. ${ }^{36}$ At the World Health Assembly in May 2017, endorsed a list of recommended interventions, called the 'Best buys' one could invest for the prevention and control of NCDs. PA promotion is one of those suggested interventions. It is estimated that implementation of the core set of 'Best buys' in NCDs will lead to a reduction in the cost of NCD-related healthcare to a minimal level of US $\$ 1$ per person in low-income 
countries and US $\$ 3$ per person in upper-middle-income countries. ${ }^{37}$ Further, to meet the challenges posed by NCDs by 2030, the year 2018 has been designated as the 'watershed' year in the global combat against NCDs and all countries were encouraged to set their preventive priorities for the control of NCDs. ${ }^{1}$

Further, it is estimated that appropriate preventive measures may avert at least one-third of premature deaths from NCDs globally every year. Thus, six different key areas have been identified by WHO in the public policy domain, which downplays the rate of progress in NCD control. Four out of these six key areas are imposed from the domestic scenario while the other two are from a global perspective. They are as follows: (1) a weak political commitment from state heads; (2) weak health systems for early detection and early intervention with accessibility and affordability issues; (3) inadequacy of the public health system informing "National policy backbones" and inappropriate progression in social and other sector participation; (4) lack of capability in contextoriented decision-making. ${ }^{1}$

Looking at the state of the Indian national policy in the context of PA promotion, it can safely be presumed that we are way behind in achieving the lofty target set on PA promotion. ${ }^{22}$ This may, in turn, affect negatively to the overall NCD target set for the years 2025 and 2030.

\section{Way forward: suggestions regarding PA promotion in the Indian NCD-care system}

1. To bring out a "National Physical Activity policy" as soon as possible. In the Indian NPAP, PA programmes and programmes on YOGA can be clubbed together to create a unique forte. It is emphasised that the purpose of 'the Indian PAG' is defeated in the absence of a strategic NPAP.

2. Securing programmes through links and digitalisation: Programme linkages can be either internal or external. Indian NCD-care model can be linked with an independent NPAP through AADHAAR-based e-health records as planned in NHP 2017. Internally, the NCDcare system is linked by the referral system. Thus, there can be a continuum of monitoring (eg, risk factor monitoring to general health monitoring) from the community to the health facilities. A universal digital health record system will lay the foundation for the integration of NPAP to health policies.

3. Programme branding and strategy: Use of an attractive, self-explanatory name for any programme along with its strategic planning against the risk factor under consideration sends a strong and clear message across all strata of audience. However, no such plans have been designed so far for the risk factor 'Physical Inactivity'. The strategic campaign against tobacco use is taken up by the 'National Tobacco Control Program' through a well-designated 'Tobacco Cessation Center' to emphasise its importance among the lay public. PA promotion cannot be a covert agenda; rather it must be displayed and acknowledged on a massive scale, considering appreciable effects of PA on multiple health outcomes.

4. Overarching population coverage: Role of proper physical activity should be emphasised equally across all age groups. Such an important health promotion tool seems to be belittled by associating it only to the nutritional disorders and obesity, relating to younger mass alone. ${ }^{21}$ A review of the content analysis of 27 national policy documents of 14 different countries in the European region has revealed that PA has been considered as an independent strategy and not as a part of obesity prevention plans. ${ }^{9}$

The National Centre of Disease Control develops training modules on prevention and control of NCDs and trains medical officers on the same. On similar lines, medical officers and physiotherapists employed in NCD cells could be trained in PA promotion.

5. Setting up of a Fully Functional Designated Centers for Health Promotion with dedicated department for PA promotion: The 12th FYP (2012-2017) had proposed to set up the National Institute of Health Promotion and Control of Chronic Diseases to be the central coordinating and facilitating agency for all the health promotion-related activities by the Government of India. ${ }^{17}$ However, this institute has not started yet functioning in its full capacity. The promotion of health education is still being done by the Central Health Education Bureau (CHEB), a subordinate organisation under the Directorate General of Health Services (DGHS) since 1956.

6. Forming a consortium for PA promotion: A consortium to promote PA should be formed as soon as possible which should include department of sports and youth affairs, health and family welfare, women and child welfare, rural and urban development, industries and labour, education, science and technology and so on. This consortium should develop a unified agenda of formulating and operationalising a population-wide PA promotion. It should identify leaders and steering agents for PA promotion from within the participating departments. For example, sports physicians or physiotherapists from the health and family welfare department may act as a leader whereas a physical education teacher can work as a steering agent. In this regard, the NPAP document of the USA ${ }^{38}$ can be an ideal document to follow.

7. Choosing among the armoury of healthcare professionals: On reviewing the policies carefully, it was noted that gaps exist between the professionals and the receiving audience. Almost everyone seems to know they should do exercise, but there is ambiguity related to the extent, duration, type and way one should exercise. Concise and accessible information must be made available in this regard.

For instance, physiotherapists are specialised and trained exercise professionals. They have the tools to assess and prescribe exercise in order to support different specialities of medicine, from paediatrics to 
geriatrics; accommodating almost all diseases and disorders. Recently, under the 12th FYP, physiotherapists have been recruited to serve at the NCD cells, musculoskeletal disorder and physical medicine centres, and rehabilitation units. While their placement is explicit, still measures to tap their full potential as professionals for promotion of PA is lacking. Physiotherapist's community-care acumen should be broadened so that it can be used for community PA plans, evaluation and monitoring of PA at the community level. Hence, the existing system itself can be used efficiently in order to produce leaders of PA promotion as per the need of the hour.

\section{CONCLUSION}

Unless appropriate swift measures are taken, NCDs will continue to be a constant threat to public health posing an enormous economic burden on our population resulting in increased untimely morbidity and mortality rates. The existing policy documents fail to appropriately weigh PA promotion as a tool for primary prevention of NCDs. India needs an independent PA policy instead of quasi-purposive policy embedded within the NCD policy. The PA promotion policy should encompass all ages and sections of the society, and it should induce primary, secondary as well as the tertiary level of prevention.

NCD-care model should be strengthened by incorporating an element clinical information system that would allow easily accessible and actionable data across all the levels of the healthcare system. The structure of the NCDcare model should be detailed and strengthened by incorporating lessons from other successfully operationalised NCD models. Indian NCD model must provide sufficient scope of interfacing individual care to that of populationbased risk factor strategies.

\section{Twitter Sandul Yasobant @dryasobant}

Acknowledgements We would like to acknowledge the help extended by Odisha Mining Corporation Ltd, Odisha, India.

Contributors All the authors have contributed to all the designated activities.

Funding The authors have not declared a specific grant for this research from any funding agency in the public, commercial or not-for-profit sectors.

Competing interests None declared.

Patient consent for publication Not required.

Provenance and peer review Not commissioned; externally peer reviewed.

Open access This is an open access article distributed in accordance with the Creative Commons Attribution Non Commercial (CC BY-NC 4.0) license, which permits others to distribute, remix, adapt, build upon this work non-commercially, and license their derivative works on different terms, provided the original work is properly cited, appropriate credit is given, any changes made indicated, and the use is non-commercial. See: http://creativecommons.org/licenses/by-nc/4.0/.

ORCID iD

Satyajit Mohanty http://orcid.org/0000-0001-9805-8953

\section{REFERENCES}

1 World Health Organization. Think piece: why is 2018 a strategically important year for NCDs? 2018. Available: http://www.who.int/ncds/ governance/high-level-commission/why-2018-important-year-forNCDs.pdf?ua $=1$

2 World Health Organization. Scaling up action against noncommunicable diseases: how much will it cost? 2011. Available: https://www.who.int/nmh/publications/cost_of_inaction/en/

3 Srivastava RK, Bachani D. Burden of NCDS, policies and programme for prevention and control of NCDs in India. Indian J Community Med 2011;36:S7-12.

4 Thakur JS, Kar S. Integration of NCD programs in India: concepts and health system perspective. Int J Med Public Health 2013;3:215.

5 Austin B. The chronic care model. MacColl Center for Health Care Innovation, 1996. Available: http://www.improvingchroniccare.org/ index.php?p=The_Chronic_Care_Model\&s=2

6 WHO. From burden to "best buys": reducing the economic impact of non-communicable diseases in low- and middle-income countries. World Economic Forum, 2011. Available: http://www.weforum.org/ EconomicsOfNCD

7 Pérez M. USA national activity plan 2003.

8 Bornstein DB, Pate RR, Pratt M, et al. A review of the national physical activity plans of six countries. J Phys Act Heal 2009;6:S245-64

9 Daugbjerg SB, Kahlmeier S, Racioppi F, et al. Promotion of physical activity in the European region: content analysis of 27 national policy documents. J Phys Act Health 2009;6:805-17.

10 WHO. NCD Country Profiles - India. World Health Organization, 2011.

11 Misra A, Nigam P, Hills AP, et al. Consensus physical activity guidelines for Asian Indians. Diabetes Technol Ther 2012;14:83-98.

12 Anjana RM, Pradeepa R, Das AK, et al. Physical activity and inactivity patterns in India-results from the ICMR-INDIAB study (Phase-1) [ICMR-INDIAB-5]. Int J Behav Nutr Phys Act 2014;11:26.

13 WHO. Non communicable diseases in the Southeast Asia region: situation and response, 2011. Available: https://apps.who.int/iris/ handle/10665/205578

14 World Heath Organization. Review of best practice in interventions to promote physical activity in developing countries, 2005. Available: https://www.who.int/dietphysicalactivity/bestpracticePA2008.pdf

15 Matsudo SM, Matsudo VR, Araujo TL, et al. The Agita São Paulo Program as a model for using physical activity to promote health. Rev Panam Salud Publica 2003;14:265-72.

16 National Centre for Disease Control (NCDC). Available: https://ncdc. gov.in/index1.php?lang=1\&level=1\&sublinkid=165\&lid=173

17 Ministry of Health and Family Welfare \& Government of India. National Health Policy, 2017, 2017. Available: https://mohfw.gov.in/ sites/default/files/9147562941489753121.pdf

18 Directorate General of Health Services. NPCDCS. Available: http:// dghs.gov.in/content/1363_3_NationalProgrammePreventionControl. aspx

19 World Heath Organization. India: first to adapt the Global Monitoring Framework on noncommunicable diseases (NCDs), 2015. Available: https://www.who.int/features/2015/ncd-india/en/

20 India Needs to do More to Stop Non-Communicable Diseases, Says Expert on WHO Report-News18. Available: https://www. news18.com/news/india/india-needs-to-do-more-to-stop-noncommunicable-diseases-says-expert-on-who-report-1767059.html

21 Planning Commission-Government of India. Report of the Working Group on Disease Burden for the 12th Five Year Plan. Vol. 3, 2013. Available: http://planningcommission.nic.in/aboutus/committee/ wrkgrp12/health/WG_3_1communicable.pdf

22 Ministry of Health and Family Welfare \& Government of India. National Action Plan and Monitoring Framework for Prevention and Control of Noncommunicable Diseases (NCDs) in IndiaDeveloped through the WHO-Government of India 2012-2013 Biennial Workplan, 2012. Available: https://www.mindbank.info/ item $/ 4882$

23 Mission Director National Health Mission. Work plan of NCD related program for Himachal Pradesh, 2014. Available: http://nrhmhp.gov. in/content/guidelines-ncd\#

24 Planning commission of India. Public health care system (Chapter VIII), 2000. Available: http://planningcommission.nic.in/aboutus/ committee/strgrp/stgp_fmlywel/sgfw_ch8.pdf

25 Partners In Health. Advocating for equity in the Global Health Discussions-NCD Synergies, 2018. Available: https:// d3n8a8pro7vhmx.cloudfront.net/pihengage/pages/585/attachments/ original/1535651493/PIH Engage - NCD Advocacy.pdf? 1535651493

26 Krishnan A, Ritvik N, Thakur JS, et al. How to effectively monitor and evaluate ncd programmes in India. Indian $\mathrm{J}$ Community Med 2011;36:57-62.

27 Anand A, Sreevatsan A, Taraporevala P. An overview of the smart cities mission in India. SCM policy brief, cent. Policy Res 2018. 
28 Ministry of youth affairs and sports (GOI). Fit India-be fit, 2019. Available: http://fitindia.gov.in/

29 Ministry of youth affairs and sports (GOI). Khelo India, 2018. Available: https://kheloindia.gov.in/

30 Ministry of Health and Family Welfare Government of India. Director General of Health Services. Available: https://dghs.gov.in/content/ 1363_3_NationalProgrammePreventionControl.aspx

31 Ministry of Health and Family Welfare Government of Himachal Pradesh. National Health Mission. Available: http://nrhmhp.gov.in/ content/guidelines-ncd

32 Ministry of Health and Family Welfare (Government of India). Parliament question \& answer. in Lok Sabha: Unstarred question no 2189, 11.12.2015 (Non communicable diseases) 1-2, 2015.

33 Global Observatory for Physical Activity. Country Card-India, 2019. Available: http://www.globalphysicalactivityobservatory.com/card/? country=IN
34 WHO. WHO | India: first to adapt the Global Monitoring Framework on noncommunicable diseases (NCDs). WHO, 2015.

35 Bachani D. National Multi-sectoral Action Plan for Prevention \& Control of NCDs in India. in Webinar on "Double-Duty" Policies for Improved Nutrition 2017:1-24.

36 Lobelo F, Stoutenberg M, Hutber A. The Exercise is Medicine Global Health Initiative: a 2014 update. Br J Sports Med 2014;48:1627-33.

37 World Health Organization. From burden to "best buys": reducing the economic impact of non-communicable diseases in low- and middleincome countries. World Economic Forum, 2011. Available: http:// www.weforum.org/EconomicsOfNCD

38 National Physical Activity Plan Alliance. US National Physical Activity Plan, 2003. Available: http://physicalactivityplan.org/docs/ 2016NPAP_Finalforwebsite.pdf 